\section{Ser uma semioticista ontem e hoje*}

\author{
On being a semioticist \\ yesterday and today
}

Diana Luz Pessoa de BARROS (USP) dianaluz@usp.br /dianaluz@mackenzie.br

Recebido em: 17 de dez. de 2019. Aceito em: 05 de fev. de 2019.

Conferência proferida no "IV Colóquio Cearense de Semiótica. Homenagem a Diana Luz Pessoa de Barros", realizado nos dias 3 e 4 de junho de 2019, na Universidade Federal do Ceará - UFC, em Fortaleza-CE.
BARROS, Diana Luz Pessoa de. Ser uma semioticista ontem e hoje. Entrepalavras, Fortaleza, v. 10, n. esp., 113-132, mai. 2020. DOI: 10.22168/2237-6321-7esp1797

Resumo: Neste depoimento que fizemos por ocasião de homenagem generosa e comovente que nos prestaram na Universidade Federal do Ceará, discutimos o que é ser uma semioticista ontem e hoje. Retomamos, assim, parte de nossa vida na universidade $\mathrm{e}$ as principais pesquisas que atualmente desenvolvemos na perspectiva da semiótica; um pouco da introdução e da história da semiótica no Brasil; as razões, de ordens diversas, que levaram os estudiosos brasileiros a embarcar na aventura semiótica; o paradigma teórico-metodológico em que a teoria se inscreve; o papel da semiótica e do semioticista na produção de conhecimento sobre a sociedade e no aprimoramento das relações sociais.

Palavras-chave: Teoria e metodologia semióticas. Papel dos estudos semióticos. Estudos do discurso e sociedade. 


\section{v. 10 (esp.}

113-132 mai.

2020

Abstract: In this modest memoir, which we have made for the occasion of a generous and moving homage to us at the Federal University of Ceará, we discuss what it means to be a semioticist yesterday and today. We depart from our life at the University and discuss the main researches that we are currently developing in the perspective of semiotics; we also discuss briefly the history and the introduction of semiotics in Brazil; the various reasons that lead Brazilian researches to undertake semiotic studies; the theoretical and methodological paradigm in which the theory is framed; the role of semiotics and of the semioticist in the production of knowledge about society and in the perfectioning of social relations.

Keywords: Semiotic theory and methodology. The role of semiotic studies. Discourse and society studies.

\section{Introdução}

Nesta homenagem que me fazem, como semioticista, começo dizendo que a semiótica está incorporada em minha vida, na forma como vejo e entendo o mundo. Ou seja, estou sempre em busca dos sentidos e dos afetos que os determinam. Poderia retomar ainda, o que disse em outro texto, citando Guimarães Rosa, que minha relação com a semiótica foi, desde o início, "inebriada". Inebriado é um bom termo para descrever meus laços passionais com a semiótica, significa segundo o Aurélio: bêbado, embriagado, extasiado, entusiasmado, enlevado.

A semiótica foi introduzida em minha vida quando aluna da graduação em São José do Rio Preto por professores que marcaram minha formação, Alceu Dias Lima, Ignácio Assis Silva e Eduardo Peñuela Cañizal, ao me ensinarem, em aulas de latim, linguística e literatura, o que significa ser professor universitário no Brasil.

Passaram-se por volta de 50 anos de perdas e ganhos: perdi minha mãe e meu irmão, ganhei minhas filhas, Mariana e Flávia, a Rosa, minha neta de 6 anos, e o Manuel, meu neto de 1 ano; muita coisa mudou na Universidade em que trabalhei e a que dei corpo e alma, e, principalmente, no País. A ditadura militar, que para mim era um divisor de águas, deixou de sê-lo para muitos e, o mais triste, até para pessoas de quem gosto; há enorme retrocesso em questões fundamentais, trabalhistas, de inclusão social, de valores, de comportamento, com a transformação do professor em inimigo público e o aumento de discursos e ações intolerantes e preconceituosos. Daí que o meu agradecimento ao Grupo de Estudos Semióticos do Ceará e à Universidade Federal do Ceará, em especial, ao Américo, ao Ricardo e à Carolina, que organizaram este evento, aos colegas, aos ex-alunos e, principalmente, aos meus amigos que aqui vieram para falar de mim e comigo e que tanto me honram e 
me comovem com a sua presença e suas falas, é, sobretudo, por estarem reconhecendo, de alguma forma, que o que fiz e em que acreditei durante mais de 50 anos, como professor, como pesquisador, como semioticista e como participante de muitas lutas pela democratização da Universidade, da educação e do país, valeu a pena. E eu que sou hoje uma professora aposentada, considerada responsável, portanto, pelo empobrecimento e crise do país. Este reconhecimento, que vocês me fazem, tornou, enfim, possível que eu continue a dizer que se de muitas coisas me arrependo, não lamento ter-me empenhado com entusiasmo nos vários papéis que assumi. Não sei se isto faz de mim uma "saudosista dos anos sessenta", que não sabe "que o sonho acabou", "uma interiorana ingênua" ou, como diriam nossos primeiros gramáticos da língua portuguesa, uma "aldeã sem juízo", o que posso dizer é que, apesar das decepções, das perdas, das tristezas e desencantos, o fato é que continuo a acreditar. Esta homenagem me faz sentir que, em algum momento de minha vida como semioticista, eu soube, fiz a hora e não esperei acontecer. Meus agradecimentos emocionados a todos vocês.

Quero agradecer ao Américo, ao Ricardo e à Carolina pela iniciativa da homenagem e pela organização competente e afetuosa do evento. Ao Fiorin, meu colega, meu companheiro de muitos encargos e também alegrias, no Departamento de Linguística da USP, e meu amigo. Foi um companheiro incansável na luta, bem sucedida, por reerguer o Departamento. Partilhamos tarefas, cursos, projetos e sucessos, etambém, as muitas atividades de docência e de orientação. À Lúcia, que assumiu comigo, com dedicação e carinho, uma parceria semiótica de muitos projetos e simpósios. Aos meus ex-orientandos, Waldir e Alexandre, de que muito me orgulho, pois são professores e pesquisadores que fazem a diferença. Ao Ivã, aluno, colega e amigo, quase filho, que com empenho, tem trabalhado muito, juntamente com o Waldir, para manter o papel fundamental da semiótica na USP e no país. Ao José Leite, que estabelece o diálogo entre a literatura e a semiótica a partir da literatura e que muito me honra com sua presença aqui. À Eliane, que desenvolve um projeto relevante sobre semiótica e educação, imprescindível hoje, e que tenho o prazer de supervisionar no pós-doutorado. À Mariana, por ser minha filha, e ainda, como me disse a Norma, por poder herdar meus livros e, eu diria, também parte de meus sonhos. Aos meus amigos, colegas desta universidade e de outras, aos meus alunos e ex-alunos que aqui estão, torcendo por mim e me prestigiando. A meus primos "cearenses", que aqui vieram carinhosamente me apoiar. 
v. 10 (esp.)

113-132 mai.

2020

\section{A semiótica no Brasil}

Retomo, agora, um pouco do que contei em meus memoriais dos vários concursos realizados, para tratar do tema desta conferência: ser uma semioticista ontem e hoje. Antônio Cândido dizia, brincando, que quando participava de bancas de concursos e examinava os memoriais acadêmicos, surpreendia-se sempre com o tanto de gente que já aos dois ou três anos de idade descobria sua vocação para os estudos da literatura. Vou correr esse risco, ao tratar do "ontem".

Começo repetindo, para que as coisas façam sentido, que nasci em Monte Aprazível, cidadezinha do interior de São Paulo, filha da professora de primeiro ano responsável pela alfabetização de quase toda a cidade e do professor de geografia do Colégio estadual. Tive infância e adolescência com todos os lugares-comuns de vida em pequenas cidades do interior: com muitos amigos e dois irmãos mais novos, brinquei na praça do coreto, andei de bicicleta nas ruas de terra, aprendi a nadar na represa, fantasiei-me no carnaval, dancei no clube local e, melhor ainda, nos bailes das cidades vizinhas, apanhei goiabas e mangas no quintal, tive o meu cinema "Paradiso", fiz roupa nova para as procissões, estudei no Grupo Escolar, aprendi piano e francês. Até me casei com o filho dos vizinhos (e ainda continuamos casados). Minha mãe alfabetizadora, organizada e persistente, expandiu em mim o conceito de língua materna e o interesse pela linguagem e pela literatura. Meu pai, mais aventureiro e membro do partido comunista, despertou-me para a leitura do mundo. Penso que essas determinações ideológicas inconscientes levaram-me ao curso de Letras e à Semiótica, apesar de, boa aluna no secundário, ter sido desestimulada por meus professores. Letras era para os "maus alunos". O presidente e o ministro da educação retomaram, atualmente, o "mote".

A semiótica discursiva foi introduzida cedo e com entusiasmo na América Latina (BARROS, 2012). Uma das razões, sem dúvida, foi o grande desenvolvimento, nesses países, da linguística saussuriana, do estruturalismo, em campos diversos, e dos vários estudos semiológicos. Esses estudos foram precursores dos estudos da semiótica discursiva, cuja introdução ocorreu, em geral, nos anos 60 e 70, bem no início, portanto da semiótica greimasiana, por professores e pesquisadores latino-americanos, que leram Semântica estrutural (GREIMAS,1976 [1966]), e perceberam ali uma nova forma de tratar da linguagem, e que tiveram alguma relação mais pessoal com Greimas (foram seus 
alunos, de forma regular ou não, na Escola de Altos Estudos em Paris ou nas visitas do mestre à América Latina). Os primeiros entusiastas da teoria semiótica formaram uma escola de semiótica em seus países na América, pois ofereceram cursos introdutórios e avançados nas universidades em que trabalhavam, escreveram livros de fundamentos, desenvolveram aspectos teóricos e metodológicos, fizeram muitas e variadas análises, traduziram, para o português e o espanhol, estudos dos semioticistas franceses. Eram muitas as tarefas do semioticista de "ontem" e essas primeiras gerações tiveram papel fundamental na implantação e desenvolvimento da semiótica na América Latina, em geral, e no Brasil, em particular.

No Brasil, a semiótica discursiva foi introduzida nos anos 60, em São Paulo, na Universidade de São Paulo e na Faculdade de São José do Rio Preto, hoje UNESP, por linguistas e estudiosos da literatura Ignácio Assis Silva, Eduardo Peñuela Cañizal, Edward Lopes, Alceu Dias Lima e Tieko Yamaguchi Miyazaki -, que acreditaram ter encontrado na semiótica um bom caminho para o exame dos sentidos dos textos e, por meio deles, para que se conhecessem melhor a sociedade e a cultura brasileiras. Fiorin e eu participamos dessa empreitada logo a seguir, com ex-alunos e colegas na universidade desses professores. Bons tempos de crenças e projetos! Muitas gerações de semioticistas surgiram desse tronco comum.

\section{A aventura semiótica}

A principal questão que, a meu ver, levou, no inicio, e ainda leva hoje, estudiosos da linguagem a se alinharem a Greimas na construção da teoria semiótica do discurso e/ou a tomarem a fundamentação teórica e a metodologia da semiótica como perspectiva e base de seus estudos foi a da proposta teórica e da metodologia seguras para a construção dos sentidos dos textos e dos discursos. Já naqueles primeiros momentos, no final dos anos 60, era uma proposta bem desenvolvida e com certo grau de formalização, para examinar textos e discursos, e uma forma de escapar das análises de livre intuição dos textos. A semiótica dava, assim, algumas respostas aos que buscavam teoria e método para examinar os textos de forma menos "intuitiva". Daí meus professores nos mandarem ler Semântica estrutural. Aos 20 anos, entendi pouco, mas senti e pressenti muito. Foi um pressentimento "inebriado", um "trunfo" para prosseguir. 
V. 10 (esp.)

113-132 mai. 2020

Vimos todos nós, a partir desse momento, o desenvolvimento da proposta, e dele participamos, que foi ganhando corpo e se tornando mais robusta: com a escolha de uma epistemologia linguística, no quadro das teorias da linguagem, e da "salvação" pelo texto (e pelo discurso), seu objeto de estudo; com o caminho metodológico fundamental do percurso gerativo da significação, grande "achado" metodológico, que deu segurança às análises; com a "fundação" nos estudos da narratividade e em seus desdobramentos, com o exame das modalidades e das paixões, a grande ruptura da proposta semiótica em relação aos estudos estruturais da narrativa anteriores; com os estudos da enunciação, de seus actantes e atores, cuja recuperação foi outro avanço da teoria semiótica.

Nesse caminho do "ontem" ao "hoje", quero destacar mais cinco razões que nos levaram a embarcar na aventura semiótica e que nos fazem, mesmo com mar revolto, nela permanecer:

- o tratamento inovador dado a questões "contextuais" e de "exterioridade discursiva", devido ao paradigma em que a teoria e a metodologia da semiótica se colocam: a semiótica discursiva não trata a "exterioridade" discursiva como "exterioridade", ou seja, como algo exterior ao texto ou ao discurso, mas não deixa de examinar, sob outro prisma e com outros nomes, aquilo que, em quadros teóricos diferentes, é denominado "exterioridade" (BARROS, 2009). As relações sócio-históricas, que participam da construção dos sentidos dos textos, são abordadas, assim, de três formas: pela análise da organização linguístico-discursiva dos textos, em especial da semântica do discurso, isto é, de seus percursos temáticos e figurativos, que revelam, de alguma forma, as determinações sócio-históricas inconscientes; pelo exame das relações intertextuais e interdiscursivas que os textos e os discursos mantêm com aqueles com que dialogam; pela relação entre duas semióticas, a do mundo natural e a das línguas naturais (ou mesmo outros sistemas semióticos), que, no dizer de Greimas (1975 [1970], p.52-56), deve ser observada não no nível das palavras e das coisas, mas no das unidades elementares de constituição dos dois sistemas de significação;

- a integração do plano da expressão no mesmo quadro teórico de exame do plano do conteúdo; 
- o alcance da proposta, que abarca os diferentes tipos de texto (verbal, visual, etc.);

- a cultura do Seminário, o papel de Greimas e a concepção da teoria semiótica como "um projeto coletivo em construção": a tradição do encontro e das discussões em grupos, que encontrávamos no Seminário de Greimas, constituiu, para muitos de nós, uma experiência nova, agradável e produtiva e mostrou-nos outro modo de se encararem a pesquisa e a produção científica e intelectual, concebidas como projetos coletivos, de que muitos participam e para cujo desenvolvimento todos contribuem com suas pesquisas individuais. Senti falta, no Brasil, desse clima de trabalho e de interesses comuns que se prolongava dos seminários, dos grupos de pesquisa e dos cursos para as mesas dos cafés. Considero o seminário de 1976 e seu período como o grande momento dos seminários de Greimas. O seminário tratou da manipulação, ou seja, de uma ruptura significativa nos estudos semióticos pela transformação da sintaxe narrativa até então examinada em uma sintaxe modal. Estou convencida de que ele foi, também, um marco na formação das novas gerações de semioticistas. Na minha, ao menos. Greimas criou, no período, o que chamávamos de meta-seminário ou de mini-seminário, para diferenciá-lo do "grande seminário". O meta-seminário era realizado depois do "grande seminário", para um grupo restrito, no gabinete de Greimas na Rue Monsieur-le-Prince. Participavam dessas reuniões semanais, portanto, apenas uns poucos pesquisadores convidados, para discussão de questões metodológicas, apresentação de obras que acabavam de ser publicadas e debates sobre projetos comuns e também sobre política acadêmica e científica. No Brasil, o Centro de Estudos Semióticos, que ajudei a fundar, fez um pouco as vezes dos seminários de Greimas e teve papel fundamental na formação de semioticistas e no desenvolvimento e na divulgação da semiótica entre nós;

- o alcance da proposta para produzir conhecimento sobre o homem em sociedade e nela interferir, de que tratarei a seguir. 
V. 10 (esp.)

113-132 mai. 2020

São, na verdade, três grandes questões: a da proposta teórica e da metodologia seguras para a construção dos sentidos dos textos e dos discursos; a do trabalho nos seminários e centros em uma construção coletiva do conhecimento, com a da figura carismática de Greimas, que nos ensinou a "confiança desconfiada"; e o alcance da proposta para produzir conhecimento sobre o homem em sociedade. Alguns foram atraídos pela primeira questão, outros pela segunda ou pela terceira. No meu caso, as três tiveram igual peso.

\section{Estudos semióticos e sociedade}

Se o semioticista de ontem foi buscar na semiótica uma proposta de análise bem desenvolvida do ponto de vista teórico e na metodologia, e, a partir daí, ingressou nesse projeto coletivo e contribuiu, em todos esses anos, para seu desenvolvimento, aumentando o alcance da teoria e produzindo novas vertentes, ele foi também assumindo deveres e obrigações com a sociedade em que vive. E hoje, cabe ao semioticista contribuir para que se entenda melhor a sociedade e, com esse conhecimento, para o aprimoramento das relações sociais. Passo a discorrer brevemente sobre o papel da semiótica na sociedade em que vivemos. Repito que os estudos da linguagem e os semióticos em particular têm papel fundamental na construção e no entendimento da sociedade por meio da língua e de seus discursos.

Examinar a sintaxe, a fonologia, a morfologia, o léxico ou os discursos de uma língua não é nunca uma descrição ou explicação mecânica desses procedimentos, mas uma forma de se conhecer a história, a cultura, a sociedade, o homem, enfim, e de abrir caminhos diretos ou indiretos para o desenvolvimento do ensino, da educação e para a organização e mudança sociais. Os estudiosos da linguagem, e os semioticistas especialmente, têm contribuído para o conhecimento da cultura e da sociedade do país, mas há ainda muito a ser feito. Por que apenas os historiadores devem falar dos "heróis nacionais" ou os sociólogos, dos sem-terra? Há outra perspectiva, outro ponto de vista, outro objeto, portanto, como diria Saussure, construído pelos semioticistas no exame dos discursos dos sem-terra ou sobre eles, do separatismo ou do racismo. E só o estudioso da linguagem e do discurso pode dar conta de descrever e explicar esse novo objeto. Tenho, nos últimos anos, trabalhado com os discursos intolerantes e preconceituosos (BARROS, 2008, 2011, 2013, 2016a, 2016b, 2016c), 
com bolsa de produtividade do $\mathrm{CNPq}$, e procurado mostrar como se constroem esses discursos, qual o papel da internet nessas elaborações e em sua divulgação, qual a ação da escola nesses casos, quais as relações entre política e intolerância. São discursos discriminatórios, preconceituosos, intolerantes, de exclusão e de incitação à violência, mantidos e exacerbados, explicitados ou mascarados. Atualmente mais explicitados, já que se perdeu a vergonha de ser intolerante, racista ou homofóbico. Em artigo sobre o discurso do excesso e o ator da enunciação excessivo (BARROS, 2016b), examinei, por exemplo, blogs e sites como "Reis do Camarote" e "Tio Astolfo, em prol da filosofia do estupro", em que encontrei, entre outros, um "guia definitivo" de como estuprar uma mulher na USP, especificamente na FFLCH, que começa dizendo:

Este é um guia para você, calouro ou veterano de um dos cursos da POLI. Você, sujeito ALPHA que está cansado destes maconheiros esquerdistas pilantras querendo dizer como você deve viver sua vida, atrasando suas aulas, usando drogas e destruindo campos.

São muitos preconceitos: machismo, misoginia, preconceito contra os estudos das humanidades e a esquerda dita intelectual.

Esses estudos, além de produzirem conhecimento sobre a intolerância e o preconceito na sociedade brasileira atual, podem também apontar os procedimentos de construção de discursos contrários, ou seja, de discursos de aceitação e intervenção social. São, nesse caso, discursos de agregação, multilinguismo, mistura, mestiçagem, diversidade sexual, pluralidade religiosa, em que os "diferentes" deixam de ser vistos como animalizados, antinaturais, anormais, doentes, feios, imorais. Esses novos discursos, em que as diferenças coexistem e dialogam entre si, são também formas de resistência social, tão necessária hoje.

Desenvolvimentos teóricos e metodológicos, exame da língua e de seus discursos são, portanto, necessários para que respostas possam ser dadas aos desafios de uma sociedade multilíngue e pluricultural, ou seja, de uma sociedade que tem a "mistura" como patrimônio.

\section{Paradigma teórico-metodológico da semiótica}

Reitero que são os estudiosos da linguagem e os semioticistas, sobretudo, que podem produzir saberes sobre a língua e seus discursos, fazer ouvir vozes em conflito e construir discursos de aceitação e de intervenção social. Não somos nós especialistas em textos e discursos? 
V. 10 (esp.)

113-132 mai. 2020

Em estudo anterior sobre Greimas (BARROS, 2017), procurei mostrar que a semiótica é a teoria adequada a esses estudos, ou mesmo que ela pede esses estudos, pois as relações da proposta semiótica com a sociedade, a história e a cultura estão já previamente dadas, devido ao paradigma teórico-metodológico em que a teoria se inscreve e a seu projeto analítico. Para tratar desse paradigma, considerei tanto os veios de origem da semiótica quanto a leitura que Greimas fez, sobretudo, de Saussure e Hjelmslev, na construção de sua proposta teórica e metodológica.

Têm sido em geral apontados três veios de origem da teoria, sempre no âmbito do estruturalismo ou do formalismo: o dos estudos linguísticos fundadores de Saussure e de Hjelmslev; o de Propp, base da sintaxe narrativa greimasiana; o das propostas de Lévi-Strauss. O estruturalismo e o formalismo foram criticados, principalmente nos anos 60 e 70, devido ao fato de, segundo os críticos, cortarem as relações do texto com a sociedade ou negarem a historicidade do discurso. Greimas, porém, se opunha ao formalismo behaviorista, que não tinha nenhuma preocupação com os sentidos e com a construção de uma teoria semântica. Esse tipo de formalismo distingue-se, para ele, da formalização necessária à construção de uma teoria científica, conforme bem apontou Fiorin (ver FIORIN, 1995).

Os veios de origem da semiótica deixam clara sua filiação aos estudos literários e antropológicos e a uma linguística em que o caráter social da língua faz parte dos princípios gerais. A semiótica proposta por Greimas tem plena inserção no âmbito das ciências humanas. Em Semântica estrutural (GREIMAS,1976 [1966]), texto fundador, ao tratar da construção de uma linguagem capaz de dar conta dos modos de existência e de manifestação da significação, o autor fala da distorção histórica da significação:

\footnotetext{
Essa construção, por sua vez, apoia-se no discurso, que é não somente o lugar de encontro do significante e do significado, mas também o lugar de distorção de significação provocada pelas exigências contraditórias da liberdade e das imposições da comunicação, pelas oposições das forças divergentes da inércia e da história (p.57).
}

Nessa mesma direção, depois de definir o lexema como lugar de encontro de sistemas sêmicos diferentes e hierarquizados, Greimas acrescenta: 
Mas o lexema é igualmente um lugar de encontro histórico. Com efeito, apesar de seu caráter fixo, o lexema é da ordem do acontecimento e se encontra, como tal, submetido à História. Isso quer dizer que, no curso da História, os lexemas se enriquecem de novos semas, mas que essa mesma História [...] pode esvaziar os lexemas de alguns de seus semas. (p. 52).

A leitura e a ressignificação que Greimas faz de Saussure, e também de Hjelmslev, de Propp ou de Lévi-Strauss, permitem-lhe, assim, dizer, em sua proposta, que no universo de sentidos dos textos está implicada uma visão de mundo, sócio-histórica portanto, como condição da significação. Isso é explicitado por ele já em sua sintaxe narrativa.

Para o exame da narratividade (BARROS, 2018), primeiro pilar de sustentação de sua construção teórica, Greimas desenvolve uma proposta de sintaxe devedora dos estudos de Propp e também dos de Tesnière. Essa sintaxe não se organiza como uma relação entre sujeito e predicado, mas como uma relação que define actantes, nome tomado da sintaxe de Tesnière (1959). Ela se aproxima, portanto, dos modelos sintáticos das gramáticas de casos de Fillmore (1968), entre outros, e não dos da sintaxe chomskyana da época. Fillmore define as relações casuais como relações sintáticas, semanticamente relevantes, que envolvem os nomes ou os sintagmas nominais e as estruturas que os contêm. Se o modelo de Chomsky, na época, é uma gramática de sujeito-predicado, para Fillmore (1968), as noções de sujeito e objeto direto devem ser excluídas do componente de base da gramática, pois, segundo o linguista, não são nem universais nem relevantes para a interpretação semântica dos enunciados. Ainda segundo o linguista, só as relações sintáticas a que são sensíveis as regras semânticas devem fazer parte do componente de base de uma gramática gerativa.

As aproximações com a sintaxe estrutural de Tesnière e com a gramática de casos de Fillmore indicam que a sintaxe narrativa da semiótica é uma sintaxe semântica (GREIMAS, 1976 [1966]) de caráter conceptual e antropológico, capaz de explicar os recortes semânticos culturais, e, para muitos, "mais ingênua" do que as semânticas lógicas e formais:

O problema que se coloca ao analista é saber como construir sua própria sintaxe semântica, que refletiria, sob a forma de invariantes, o conjunto dos jogos sintáticos que são representados, como outras tantas variáveis, sobre escalões hierárquicos diferentes. Isso porque essa sintaxe permanecerá sempre semântica, apesar das ilusões dos lógicos, que pensam poder operar com formas sem significação. Estamos definitivamente fechados no nosso universo semântico, e o 
v. 10 (esp.

$113-132$ mai.

2020 melhor que podemos fazer é ainda tomar consciência da visão de mundo que aí se acha implicada, ao mesmo tempo, como significação e como condição dessa significação (GREIMAS, 1976, p.155)

No nível discursivo do plano do conteúdo, a organização enunciativa das pessoas, do tempo e do espaço traz também pistas das determinações sócio-históricas dos atores da enunciação, e do texto, portanto, mas é, sobretudo, nos temas e figuras que elas mais se deixam ver ou entrever. Segundo Fiorin (1988, p.1-19), a semântica discursiva depende mais diretamente de fatores sociais, apresenta-se como o campo da determinação ideológica inconsciente, e é o nível em que as determinações sócio-históricas ocorrem de forma mais cabal.

Resta dizer que Greimas recusa interpretações extralinguísticas do texto, o que não significa que ele ignore o papel do contexto e do conhecimento do mundo na construção da significação, mas que defina o contexto como contexto "interno" ou como outros textos, todos eles passíveis de análise. Conforme já observei, o exame da "exterioridade" (BARROS, 2009), na perspectiva semiótica, assume, portanto, rumos seguros e diferenciados, sem recorrer, porém, ao extralinguístico ou ao extradiscursivo: uma das direções considera as relações do texto com sua historicidade, analisando, sobretudo, os temas e figuras do discurso e os laços intertextuais e interdiscursivos; a outra examina as correlações entre os sistemas de significação e o mundo, considerado também como uma semiótica.

Em síntese, ao se construir no âmbito do estruturalismo, a partir do discurso fundador de Saussure, com sua língua social, e também com base nos estudos literários e culturais dos formalistas russos e da antropologia, ressignificados, Greimas deu à sua proposta características do estruturalismo, pois propõe o exame da organização ou da estrutura do texto e apresenta como tarefa de seus estudiosos a análise dos procedimentos e estratégias inumeráveis e diversificados de construção dos sentidos e, ao mesmo tempo, mostra que essa organização do discurso contém uma visão de mundo. Diz ele (1976 [1966]):

O jogo sintático que consiste em reproduzir cada vez, em milhões de exemplares, um mesmo pequeno espetáculo que comporta um processo, alguns atores e uma situação mais ou menos circunstanciada, talvez seja falseado e não corresponda à maneira de ser das coisas do mundo "real". Isso não impede que o que desenrolamos diante de nós pelas regras sintáticas seja nossa visão de mundo e nossa maneira de organizá-lo [...]. 


\section{Projetos de pesquisa em desenvolvimento}

Atualmente, e já há algum tempo, desenvolvo três projetos e, com eles, mantenho minhas preocupações no campo dos estudos linguísticos e semióticos: a de contribuir para que, por meio dos estudos do discurso, se conheça melhor a cultura e a sociedade, sobretudo brasileiras; a de concorrer para o desenvolvimento da teoria e da metodologia semióticas, sobretudo pelo alargamento de seu campo e objeto de estudo. Os projetos são:

- Estudos sobre a comunicação e a interação em língua falada: esses estudos estão sendo desenvolvidos no âmbito do projeto NURC-SP (Projeto de Estudo da Norma Linguística Urbana Culta de São Paulo), em que assumi a perspectiva da semiótica discursiva francesa, que faço dialogar com outros estudos da língua falada e, principalmente, com os da chamada Análise da Conversação; o objetivo principal do projeto, no momento, é refletir, semioticamente, sobre as modalidades falada e escrita da língua e, com esse estudo, apontar alguns caminhos para o ensino de língua, literatura e comunicação e para o exame dos discursos na internet, caracterizados pela complexidade entre a fala e a escrita;

- Conceitos e imagens da norma nas gramáticas do português, do século XVI à atualidade: a pesquisa tem os objetivos de estabelecer a diversidade de conceitos e de imagens da norma no português do século XVI à atualidade, de estabelecer a organização discursiva das gramáticas e os diferentes conceitos e imagens de norma e de língua construídos; de verificar se os discursos da norma são diferentes nas gramáticas portuguesas e brasileiras e nos diferentes momentos, e indicar, assim, alguns dos caminhos percorridos, do século XVI até hoje, para a constituição da "língua nacional" no Brasil; o projeto de exame das gramáticas fundamenta-se também na teoria e metodologia da Semiótica discursiva, quadro em que as gramáticas são analisadas como discursos e é essa questão teórico-metodológica que diferencia este projeto de outras formas de conceber a história das ideias linguísticas; 
v. 10 (esp.

113-132 mai. 2020

- Preconceito e intolerância em relação à linguagem: fizemos já referência ao projeto, que tem por objetivos mostrar como se constroem os discursos intolerantes (racista, fascista, purista, sexista, etc.), quais os procedimentos linguísticos e discursivos usados nessa construção e em que quadro de valores esses discursos se inserem; de apontar como discursos de diferentes tipos, modalidades e gêneros podem ser considerados discursos intolerantes (discursos políticos, gramaticais, na internet, etc.); de aprimorar uma proposta teórica e metodológica, no âmbito dos estudos da linguagem, para exame dos discursos intolerantes, sem deixar de considerar a necessidade de estudos multidisciplinares; de contribuir, na perspectiva dos estudos da linguagem, com os estudos sobre a intolerância nos diferentes campos do conhecimento (história, sociologia, psicologia, etc).

O trabalho que está sendo atualmente elaborado insere-se nesse terceiro projeto. Para concluir, então, esta conferência-depoimento apresentarei, muito resumidamente, alguns de seus resultados parciais. O estudo trata de questões de veridicção e de modalização pelo saber e pelo crer na produção e interpretação de fake news, de revisões do passado e da história e de simulações de ocupação por um mesmo ator dos papéis de sujeito e oponente, de destinador e de destinatário.

A semiótica discursiva tem tratado das questões da verdade dos discursos com os estudos da modalização (modalização pelo saber e pelo crer, modalização veridictória). Na veridicção, as relações modais entre o ser e o parecer, que determinam os discursos como verdadeiros, mentirosos, secretos ou falsos, e levam seus destinatários a neles acreditar ou não, têm na internet características próprias. Se os textos de "histórias de pescador" são, por definição, interpretados como falsos, isto é, que nem parecem nem são verdadeiros, os da internet são, em geral, considerados verdadeiros, ou seja, que parecem e são verdadeiros, e, mais do que isso, que eles são discursos que desmascaram a mentira ou revelam o segredo. O destinatário de discursos interpreta-os a partir de seus conhecimentos e crenças e da capacidade de persuasão do destinador-manipulador. No caso da internet (BARROS, 2015), a interpretação como discurso verdadeiro e também o desmascaramento da mentira e a revelação do segredo decorrem do efeito de sentido de grande quantidade de saber armazenado pela internet ("que sabe tudo") e do de interatividade acentuada, pois, com esses atributos de 
seu discurso, o destinador é colocado, pelo destinatário interpretante, na posição de sujeito do saber. Soma-se a esses procedimentos de persuasão e interpretação dos discursos na internet, o de o destinatário, devido à interatividade intensa já mencionada, deles se considerar, em boa parte, também como "autor-destinador". Assim construído, o destinatário acredita e confia nos discursos que também são "seus".

A pós-verdade pode ser entendida, no quadro da veridicção, como resultante de interpretação baseada, sobretudo ou apenas, nas crenças e emoções do destinatário interpretante. Dessa forma, por mais absurdos que pareçam, os discursos cujos valores estiverem de acordo com as crenças e sentimentos do destinatário serão por ele considerados verdadeiros. Um bom exemplo, no Brasil, é o discurso que afirma, hoje, que a terra é plana...

A releitura do passado e da História é mais uma das estratégias usadas para a formação da pós-verdade, para a criação de valores e crenças que sustentem os valores de determinados grupos e partido e, em última instância, para produzir as condições ou o terreno em que possam germinar notícias falsas e outros tipos de discursos fundamentados na mentira. Tomemos como exemplo a revisão proposta pelo chanceler Ernesto Araújo, a partir de textos e falas de Olavo de Carvalho, em relação ao nazismo. Como o grupo prega o nacionalismo intenso, foi preciso relacionar o nacionalismo do nazismo e do fascismo não mais à extrema-direita, mas ao comunismo e à esquerda em geral.
Uma coisa que eu falo muito e é muito uma tendência da esquerda: pega uma coisa boa [o nacionalismo], sequestra, perverte e transforma em uma coisa ruim. Acho que é mais ou menos o que aconteceu sempre com esses regimes totalitários. Isso tem a ver com o que eu digo, que fascismo e nazismo são fenômenos de esquerda.

De nada adiantou a manifestação, em setembro de 2018, do embaixador da Alemanha no Brasil, Georg Witschel, que, em entrevista ao jornal o Globo, disse:

"é uma besteira argumentar que o fascismo e o nazismo são movimentos da esquerda. Isso não é fundamentado, é um erro, é simplesmente uma besteira.

Ou as manifestações de historiadores brasileiros e estrangeiros que mostraram ser historicamente incorreto, ou mesmo um absurdo, associar o nazismo a um movimento de esquerda e que, ao dizer isso, o ministro "falsifica a História", comete "uma fraude intelectual", "deturpa 
v. 10 (esp.)

113-132 mai. 2020

o passado", diz um "disparate" e uma "asneira", realiza um "ato perigoso" para a política externa brasileira.

Fica claro que o debate científico histórico sobre a questão não é levado em consideração e que a visão do passado e da História prende-se apenas a questões político-ideológicas. Esse tipo de discurso é um discurso do acontecimento, no âmbito das crenças e valores que importam para o jogo político daqueles que o sustentam. Mostra-se aí também o anti-intelectualismo que, no dizer de Fiorin (2019), é um dos traços característicos do discurso da extrema-direita e que marca também, como já apontei, os discursos intolerantes excessivos que examinei na internet.

Quando a interpretação só leva em conta as crenças e emoções do destinatário que interpreta, está preparado o solo em que germinarão os discursos fundamentados na mentira, como as notícias falsas ou a simulação de sincretismo actorial.

A produção e disseminação desses textos mentirosos ou falsos são estratégias de persuasão usadas pelo destinador para convencer o destinatário a neles acreditar e a agir a partir dessa crença. Vejamos agora, rapidamente, os dois tipos mencionados de construções discursivas fundamentadas na mentira.

Um texto pode ser interpretado como verdadeiro ou falso, ou considerado como uma mentira ou um segredo. Cada texto constrói a sua verdade. Se o texto for mal elaborado, usar estratégias inadequadas, organizar-se de forma contraditória, não seguir o padrão do gênero ou o estilo de língua apropriado, ele poderá ser "desmascarado" com base em sua composição interna ou estilo problemáticos. Se ele for, porém, um texto bem elaborado em todos os níveis de organização, não será possível interpretá-lo como falso ou como mentiroso sem o recurso a outros textos. Vejamos exemplos das notícias falsas dos dois casos.

Um vídeo, divulgado em 2019 no WhatsApp, apresenta, longamente, uma fazenda fantástica em Tocantins, enorme, bem cuidada, maravilhosa, de terra boa, em estrada nova e asfaltada, e mostra, no final, a placa da fazenda, que diz:

Fazenda

NOSSA SENHORA APARECIDA

Prop. LULA E FAMÍLIA

BARROLÂNDIA - TO 
Nesse texto, é possível desmascarar a mentira, pela "ingenuidade" de colocar no gênero placa de indicação de propriedade apenas o apelido ou parte do nome do ex-presidente, de quem se quer mostrar o enriquecimento ilícito. Entre as pessoas que acreditaram na notícia falsa, houve muitos que sugeriram atentados à Fazenda, o que causou transtornos a seus verdadeiros proprietários, segundo manifestações deles.

Já neste novo exemplo, também do WhatsApp, só outros textos podem colocar em dúvida sua verdade:

Figura 1 - Notícia falsa sobre manifestação na Avenida Paulista em 07/04/2019.

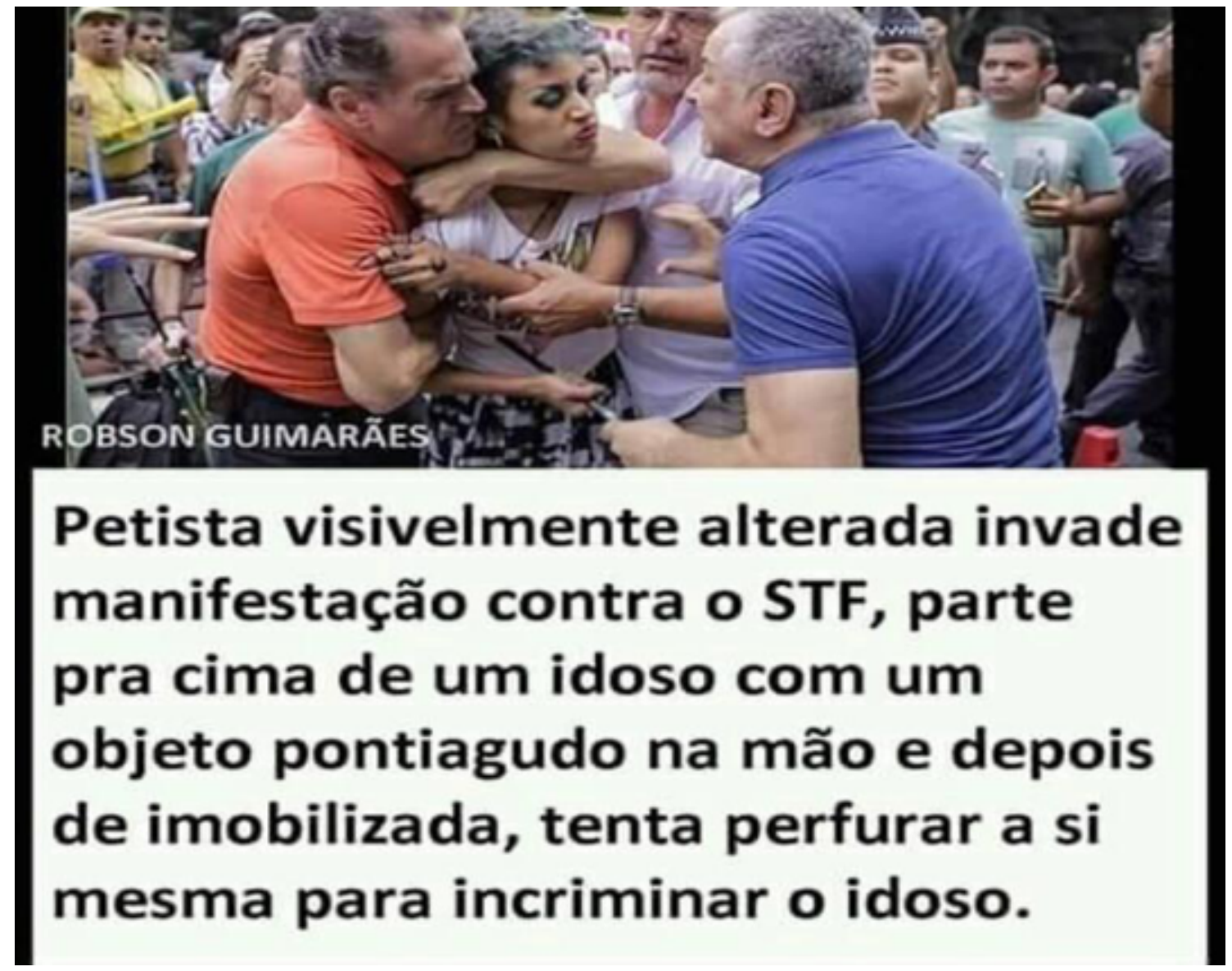

Fonte: WhatsApp.

O caráter mentiroso da mensagem pode ser detectado quando ela é comparada com a mesma foto que foi publicada na primeira página da Folha de S. Paulo, no dia 8 de abril de 2019, no dia seguinte, portanto, ao acontecimento, com a seguinte legenda: 
v. 10 (esp.

$113-132$ mai.

2020 presidente, cuja prisão completou um ano, e de manifestação para apoiar a Operação Lava Jato e a condenação do petista.

Passo agora aos discursos com a estratégia do sincretismo actorial. Greimas (2014 [1983]) mostrou que a relação entre o actante sintático e o ator semântico não é sempre de um para um, ou seja, nem sempre um ator reveste semanticamente um só actante, ou um actante é preenchido por apenas um ator. É possível que um mesmo ator exerça vários papéis actanciais e, nesse caso, o texto trará uma perspectiva psicologizante do mundo, ou que um actante seja preenchido por vários atores, e, então, a visão do texto será sociologizante.

É do primeiro tipo que vou tratar aqui. Nesse caso, há duas possibilidades veridictórias: textos em que um ator cumpre vários papéis actanciais e outros em que ele apenas parece fazê-lo e usa essa mentira como estratégia discursiva para isentar-se das responsabilidades de cada uma das posições que finge ocupar e, ao mesmo tempo, para assegurar as vantagens desses vários papéis. É esse jogo de posições, modalizado veridictoriamente como mentira, que atualmente ocorre, por exemplo, nos discursos governamentais no Brasil. O ator "presidente" constróise como um termo complexo, no nível do parecer, pois simula ocupar as posições actanciais de sujeito e de antissujeito ou oponente (governo e oposição) ou, ainda, de destinador e de destinatário-sujeito (governante e governados). Em outras palavras, um mesmo ator finge ocupar todos os papéis da narrativa que produz. Daí a construção de inimigos internos no próprio governo e as disputas com os ministros, com a ala militar de seu governo ou com seu vice-presidente. Daí também a possibilidade e a facilidade de desdizer-se e de voltar atrás, pois o ator se manifesta de posições actanciais diferentes e opostas. Daí ainda o reforço de seus valores e perspectivas, porque se um dos lugares que ocupa vence a disputa é sempre ele ou membros de seu governo que estão nesse lugar. Daí principalmente a falta de espaço para uma verdadeira oposição, pois todos os lugares da narrativa já estão ocupados por um só ator. Esta é uma estratégia política de grande alcance e tonicidade fundamentada na mentira.

\section{Considerações finais}

O ódio resulta, nos discursos intolerantes, da interpretação pelo intolerante de que o sujeito odiado não cumpriu certos contratos sociais e é culpado pelos males que o intolerante e a sociedade de que 
faz parte sofrem. As mentiras nas notícias falsas, nas revisões absurdas da história e nas simulações de sincretismo actorial procuram apontar os "maus cidadãos" que, no quadro de valores do destinador-produtor das mentiras, não são ou não foram fiéis aos contratos sociais e devem ser, portanto, odiados e temidos pelos danos que causaram e ainda causam e punidos com ações intolerantes de vingança. A generalização indevida, que caracteriza os discursos da extrema-direita (FIORIN, 2019) e as notícias falsas, em especial, é um dos procedimentos dos discursos intolerantes. Ao sancionar os homossexuais como promíscuos ou os árabes como fanáticos, nos discursos intolerantes, faz-se uma generalização indevida e atribui-se a um grupo social um traço particular de um indivíduo. Por essa razão, os textos que aproximamos por suas características discursivas e sua fundamentação na mentira são discursos do ódio e desencadeadores de ações discriminatórias contra os grupos sociais construídos por essa generalização impossível: os pobres, quando dependem do programa de bolsa-família, são sempre preguiçosos que vivem às custas dos ricos, que trabalham; os políticos de esquerda, todos eles e mais os eleitores que os apoiam, enriquecem ilicitamente; todo artista se aproveita de subsídios do governo; os professores e intelectuais "deformam" os estudantes brasileiros ao defenderem os direitos humanos, a inclusão do diferente, o acesso às artes, à cultura e à ciência. Daí esse mundo de mentira e de ódio, em que estamos vivendo hoje.

No tempo que me resta de vida e de lucidez, vou investir, cada vez mais, em produzir, por meio dos estudos semióticos, conhecimento sobre a sociedade em que vivo e, também, em contribuir para que meus netos aprendam a bem ler o mundo.

Agradeço uma vez mais, muito comovida, a todos vocês, por esta homenagem, de amor e de amizade verdadeiros.

\section{Referências}

BARROS, Diana Luz Pessoa de. Preconceito e intolerância em gramática do português. In: Diana Luz Pessoa de Barros; José Luiz Fiorin (orgs.) A fabricação dos sentidos. Estudos em homenagem a Izidoro Blikstein. São Paulo: Humanitas, 2008, p. 339-363.

BARROS, Diana Luz Pessoa de. Uma reflexão semiótica sobre a "exterioridade" discursiva. ALFA. Revista de Linguística 53 (2): 351-364, 2009.

BARROS, Diana Luz Pessoa de. (org.) Preconceito e intolerância. Reflexões linguístico-discursivas. São Paulo: Editora Mackenzie, 2011. 
v. 10 (esp.)

$113-132$ mai. 2020

BARROS, Diana Luz Pessoa de. A semiótica no Brasil e na América do Sul: rumos, papéis e desvios. RELIN, 20 (1): 149-186, 2012.

BARROS, Diana Luz Pessoa de. Política e intolerância. In: Oriana Fulaneti e Alexandre Marcelo Bueno (orgs.). Linguagem e política: princípios teóricodiscursivos. São Paulo: Contexto, 2013, p.71- 92.

BARROS, Diana Luz Pessoa de. A complexidade discursiva na internet. CASA. Cadernos de Semiótica Aplicada. 13: 13-31, 2015.

BARROS, Diana Luz Pessoa de. (org.). Margens, periferias, fronteiras: estudos linguístico-discursivos das diversidades e intolerâncias. São Paulo: Editora Mackenzie, 2016a.

BARROS, Diana Luz Pessoa de. Estudos discursivos da intolerância: o ator da enunciação excessivo. Cadernos de Estudos Linguísticos. 58: 7-24, 2016b.

BARROS, Diana Luz Pessoa de. Intolerância e ensino. In: Neusa Barbosa Bastos (org.). Língua portuguesa e lusofonia: história, cultura e sociedade. São Paulo: Eđuc, 2016c, p.195-210.

BARROS, Diana Luz Pessoa de. Les études de société selon la perspective de la sémiotique greimassienne. Semiotica (Berlin). 214 : 373-391, 2017

BARROS, Diana Luz Pessoa de. La construction de la syntaxe narrative: histoire et perspectives. Dilbilim Dergisi, 32 : 103-114, 2014/2, Ankara 2018.

FILLMORE, Charles. The case for case. In: E. Bach and R. T. Harmrs (ed.) Universals in linguistics theory. New York: Holt, Reinehart and Winston, 1968.

FIORIN, José Luiz. Linguagem e Ideologia. São Paulo: Ática, 1988.

FIORIN, José Luiz. Semântica estrutural: o discurso fundador. In: Ana Cláudia de Oliveira; Eric Landowski (org.). Do inteligível ao sensível. São Paulo: EDUC, 1995, p. $17-42$.

FIORIN, José Luiz. Operações enunciativas do discurso da extrema-direita. Discurso \& Sociedad. 13(3):370-382, 2019

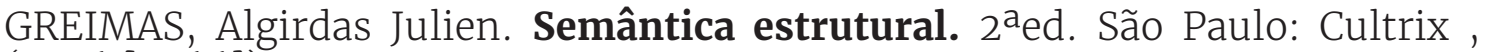
$(1976[1966])$.

GREIMAS, Algirdas Julien. Sobre o sentido: ensaios semióticos. Petrópolis: Vozes, 1975 [1970].

GREIMAS, Algirdas Julien. Sobre o sentido II. São Paulo, Nankin, EDUSP, 2014 [1983].

TESNIÈRE, Lucien. Éléments de syntaxe structurale. Paris: Klincksieck, 1959. 